P-ISSN 2580 - 7781

E-ISSN 2615 - 3238

\title{
ANALISIS PEMAHAMAN SISWA TERHADAP MATERI FISIKA SMA BESARAN, SATUAN, DAN PENGUKURAN DI MAN 2 KOTA JAMBI
}

\section{ANALYSIS OF STUDENTS UNDERSTANDING OF HIGH SCHOOL PHYSICS MATERIAL QUANTITIES, UNITS, AND MEASUREMENTS IN MAN 2 KOTA JAMBI}

\author{
Fitriani $^{1)}$, Lega Cantika ${ }^{2)}$, Nola Lolita ${ }^{3)}$ \\ ${ }^{123}$ Prodi Pendidikan Fisika, FKIP, Universitas Jambi \\ ${ }^{1}$ Email: 06fitriani@gmail.com
}

\begin{abstract}
ABSTRAK
Sekarang fisika dianggap salah satu pembelajaran yang sulit oleh sebagian besar siswa, yang membuat turunnya minat belajar siswa terhadap pembelajaran fisika. Kenyataan di lapangan banyak menunjukkan bahwa hasil belajar atau prestasi belajar siswa terhadap pembelajaran fisika rata-rata masih dalam kategori cukup.Penelitian ini bertujuan untuk menganalisis pemahaman siswa terhadap materi fisika besaran, satuan, dan pengukuran terhadap siswa/siswi kelas X MIA 1 dan 2 di MAN 2 Kota Jambi. Pemahaman siswa terhadap materi besaran, satuan, dan pengukuran akan dilihat dari data yang terkumpul melalui teknik pengumpulan data secara kuesioner/penyebaran angket berupa soal fisika materi besaran, satuan, dan pengukuran. Dari uji data normalitas dapat di ketahui bahwa pemahaman siswa terhadap materi besaran, satuan, dan pengukuran rata-rata 64,7 yang bisa dikategorikan cukup. Maka, diperlukan evaluasi lebih lanjut terhadap proses pembelajaran untuk meningkatkan hasil belajar/pemahaman siswa terhadap materi fisika. Kata kunci: Pemahaman Siswa, Fisika Sulit, Hasil belajar.
\end{abstract}

\section{ABSTRACT}

Now physics is considered one of the difficult lessons by most students, which makes students' interest in learning physics decline. The reality in the field shows that the learning outcomes or student achievement on average physics learning are still in the sufficient category. This study aims to analyze students' understanding of the physics material of quantities, units, and measurements of class X MIA 1 and 2 students in MAN 2 Jambi City. Students' understanding of the material quantities, units, and measurements will be seen from the data collected through data collection techniques by means of questionnaires / questionnaires in the form of physical questions of material quantities, units and measurements. From the normality data test, it can be seen that students' understanding of the material quantity, unit, and average measurement is 64.7 which can be categorized as sufficient. So, further evaluation of the learning process is needed to improve student learning outcomes / understanding of physics material.

Keywords: Students' understanding, Physics is difficult, Learning outcomes.

\section{PENDAHULUAN}

Pendidikan merupakan proses dalam rangka mempengaruhi peserta didik agar mampu menyesuaikan diri sebaik mungkin dengan lingkungannya, sehingga akan menimbulkan perubahan dalam dirinya. Sekolah merupakan salah satu 
tempat berlangsungnya proses pendidikan melalui kegiatan belajar mengajar antara guru dengan siswa (Oktaviana, 2016:7).

Pendidikan merupakan suatu wadah untuk meningkatkan kreatifitas dan pemahaman ilmu pengetahuan anak bangsa, dengan adanya pendidikan mampu mengubah pola pikir dan mencerdaskan anak. Pendidikan bisa didapat dari mana saja baik di sekolah ataupun di rumah. Di rumah orang tua sangat berperan penting untuk pendidikan bagi anak, berbeda dengan di sekolah di mana guru lah yang berperan penting dalam proses pengembangan pengetahuan anak.

Di sekolah pendidikan yang di ajarkan oleh guru dapat berlangsung melalui proses belajar mengajar, di mana guru yang menjadi fasilitator yang menyampaikan setiap pemahaman terhadap siswa dan siswalah yang menerima apa-apa saja yang diajarkan oleh guru. Pembelajaran disekolah ada banyak sekali materi dan ilmu pengetahuan yang di ajarkan, salah satunya yaitu mata pelajaran fisika.

Pembelajaran Fisika di sekolah merupakan hal yang penting dalam keterlibatan mencerdaskan kehidupan bangsa, karena dengan adanya pembelajaran Fisika peserta didik dilatih untuk dapat memahami berbagai hal dan fenomena yang terjadi di alam dan mengetahui keterkaitannya dengan ilmu yang ada (Dani, 2019:25). Fisika merupakan ilmu yang bertujuan untuk mendidik siswa, agar dapat berpikir logis, kritis, memiliki sifat obyektif, disiplin dalam menyelesaikan permasalahan baik dalam bidang fisika, bidang lain, maupun dalam kehidupan sehari-hari sehingga fisika perlu dipelajari dan diaplikasikan. Namun kenyataan di lapangan, pelajaran fisika masih diangap sebagian siswa sebagai pelajaran yang tidak menarik dan sulit untuk dipahami (Purwanto, 2016:22).

Namun, sayangnya di sekolah pelajaran fisika kurang banyak diminati dan disukai, karena kebanyakan siswa merasa bahwa pelajaran fisika merupakan pelajaran yang amat sukar, hal ini sesuai juga dengan pendapat Kurnia (2016:55) dalam penelitian yang mengemukakan, "Hal ini terlihat dari observasi dikelas X MIA di SMA Negeri 4 Kota Jambi. Berdasarkan wawancara dengan beberapa siswa didapat pelajaran fisika itu sulit, menyeramkan, tidak menarik, serta 
membosankan, sehingga fisika menjadi mata pelajaran yang tidak disenangi, patut ditakuti dan dibenci. Hal ini juga terjadi di SMA Negeri 11 Kota Jambi, selain memiliki persepsi negatif terhadap mata pelajaran fisika juga terhadap guru fisika dimana siswa kurang menyukai guru fisika oleh karena itu siswa menjadi malas dan kurang menyukai fisika."

Selain pola pikir siswa yang menganggap fisika itu sulit, juga terdapat hal lain yang membuat kurangnya minat belajar siswa terhadap fisika, yaitu seperti metode yang digunakan guru dalam mengajar terkesan membosankan, padahal menurut Anggraini dalam (Taqwa, 2019:7) sejatinya pembelajaran fisika tidak hanya sebatas mencapai goal dalam hal mentransfer fakta, konsep, prinsip, maupun hukum semata, melainkan siswa/mahasiswa diharapkan agar dapat menguasai seluruhnya melalui proses penemuan.

Kurangnya minat belajar siswa tersebut, merupakan salah satu faktor internal. Faktor internal merupakan faktor-faktor yang berasal dari diri peserta didik yang mempengaruhi hasil belajar. Salah satu faktor fisiologis yang meliputi motivasi belajar, minat belajar, dan kebiasaan belajar (Jufrida, 2019:32).

Dengan adanya mindset peserta didik yang buruk terhadap fisika tentu saja hal itu akan mempengaruhi hasil belajar siswa, maka dari itu peneliti melakukan sebuah penelitian untuk melihat pemahaman siswa dan hasil belajar siswa terhadap materi fisika besaran, satuan dan pengukuran di MAN 2 Kota Jambi. Di SMA materi besaran, satuan, dan pengukuran merupakan materi dasar dan awal yang dipelajari oleh peserta didik, maka dari itu peneliti ingin melihat dengan cara menyebarkan angket yang berisikan soal menganai materi besaran, satuan, dan pengukuran sebanyak 25 butir, dan akan dilihat hasil belajar siswa sehingga nantinya dapat dilihat apakan mindset buruk siswa terhadap fisika mempengaruhi hasil belajar siswa.

\section{METODE PENELITIAN}

Adapun jenis penelitian ini adalah jenis penelitian deskriptif, di mana tahap penelitian dimulai dengan cara menyebarkan kuesioner/angket kepada siswa kelas X MIA 1 dan 2 di MAN 2 Kota Jambi, lalu setelah data terkumpul barulah data di uji dan dianalisis, teknik pengumpulan data yang digunakan dalam penelitian ini 
P-ISSN 2580 - 7781

E-ISSN 2615 - 3238

berupa angket/kuesioner yang yang berisikan 25 butir soal mengenai materi besaran, satuan, dan pengukuran yang harus diisi oleh siswa kelas X MIA 1 dan 2 di MAN 2 Kota Jambi. Teknik analasis data berupa analisis deskriptif setelah data terkumpul. Subyek penelitian ini menggunakan siswa kelas X MIA 1 dan 2 di MAN 2 Kota Jambi yang dilaksanakan pada tanggal 23 Oktober dengan menyebarkan angket kepada siswa melalui google form, kerena sekolah ditutup karena adanya pandemic maka terpaksa untuk pengumpulan data berupa kuesioner dilakukan secara online.

\section{HASIL PENELITIAN DAN PEMBAHASAN}

Materi besaran, satuan, dan pengukuran merupakan materi awal yang dipelajari oleh siswa di SMA yang mencakup mengeni bagaimana penggunaan alat ukur yang benar, cara melakukan pengukuran yang benar, dan mengenal besaran pokok maupun besaran turunan, serta satuan-satuan yang baku atau satuan yang benar menurut SI.

Setelah data terkumpul dari angket yang telah disebarkan kepada siswa, maka data akan diuji dan diolah melalui SPSS statistic 21, pada tahap pertama data diuji melalui uji normalitas, maka di dapatkan hasil seperti gambar di bawah:

\begin{tabular}{|c|c|c|c|c|}
\hline & & & Statistic & Std. Error \\
\hline \multirow[t]{13}{*}{ Angket Soal Kelas X } & \multicolumn{2}{|l|}{ Mean } & 64.7000 & 1.75930 \\
\hline & \multirow[t]{2}{*}{$95 \%$ Confidence Interval for Mean } & Lower Bound & 61.1415 & \\
\hline & & Upper Bound & 68.2585 & \\
\hline & $5 \%$ Trimmed Mean & & 64.8889 & \\
\hline & Median & & 64.0000 & \\
\hline & Variance & & 123.805 & \\
\hline & Std. Deviation & & 11.12678 & \\
\hline & Minimum & & 40.00 & \\
\hline & Maximum & & 88.00 & \\
\hline & Range & & 48.00 & \\
\hline & Interquartile Range & & 16.00 & \\
\hline & Skewness & & -.160 & .374 \\
\hline & Kurtosis & & -.176 & .733 \\
\hline
\end{tabular}

Gambar 1. Descriptives uji normalitas.

Dari gambar di atas dapat di lihat bahwa dari kuesioner yang berisikan 25 butir soal mengenai materi besaran, satuan, dan pengukuran. Nilai maksimum yang di peroleh oleh siswa yaitu sebesar 88, yang artinya dari 25 soal jumlah soal benar yang mampu dijawab oleh siswa adalah 22 butir. Sedangkan untuk nilai 
P-ISSN 2580 - 7781

E-ISSN $2615-3238$

minimum yang diperoleh siswa yaitu sebesar 40, yang artinya siswa dari 25 jumlah soal siswa hanya berhasil menjawab sebanyak 10 soal dengan benar. Dan nilai rata-rata yang diperoleh oleh siswa kelas X MIA 1 dan 2 MAN 2 Kota Jambi yaitu sebesar 64,7\%, dengan nilai tengah atau median sebesar 64,00 dengan standar deviasi sebesar 11,12678. Hasil ini menunjukkan bahwa hasil belajar dan pemahaman siswa kelas X MIA 1 dan 2 di MAN 2 Kota jambi bisa dikategorikan cukup.

\begin{tabular}{|l|r|r|r|r|r|c|}
\multicolumn{9}{|c|}{ Tests of Normality } \\
\hline & \multicolumn{3}{|c|}{ Kolmogorov-Smirnov } & \multicolumn{3}{|c|}{ Shapiro-Wilk } \\
\cline { 2 - 7 } & Statistic & \multicolumn{1}{c|}{ df } & \multicolumn{1}{c|}{ Sig. } & Statistic & \multicolumn{1}{c|}{ df } & Sig. \\
\hline Angket Soal Kelas X & .125 & 40 & .116 & .975 & 40 & .502 \\
\hline
\end{tabular}

Gambar 2. Test of Normality uji normalitas.

Berdasarkan tabel ouput di atas diketahui nilai sig. untuk hasil belajar siswa kelas X MIA 1 dan 2 sebesar 0,502. karena nilai Sig. untuk kedua kelas tersebut $>0,05$, maka sebagaimana dasar pengambilan keputusan dalam uji normalitas di atas, dapat disimpulkan bahwa data hail belajar kelas X MIA 1 dan 2 berdistribusi normal.

Untuk mengetahui perbandingan antara hasil belajar siswa kelas MIA 1 dan 2 dari uji independent sample test, maka hasil pengujian dapat digambarkan melalui gambar di bawah:

Group Statistics

\begin{tabular}{|ll|r|r|r|r|}
\hline & Kelas & N & Mean & Std. Deviation & $\begin{array}{c}\text { Std. Error } \\
\text { Mean }\end{array}$ \\
\hline Hasil Belajar Kelas X & X MIA 1 & 20 & 64.400 & 10.2104 & 2.2831 \\
& X MIA 2 & 20 & 65.000 & 12.2345 & 2.7357 \\
\hline
\end{tabular}

Gambar 3. Output group statistics.

Berdasarkan tabel ouput di atas diketahui bahwa jumlah data hasil belajar sebanyak 20 orang untuk masing-masing kelas. Nilai rata-rata hasil belajar siswa atau mean untuk kelas MIA 1 adalah 64,40, sementara untuk kelas MIA 2 sebesar 65,00. Dengan demikian secara deskriptif statistik dapat disimpulkan ada perbedaan rata-rata hasil belajar siswa antara kelas MIA 1 dan MIA 2. Selanjutnya 
P-ISSN 2580 - 7781

E-ISSN 2615 - 3238

untuk membuktikan bahwa perbedaan itu signifikan atau tidak dapat kita lihat pada output Independent Sample Test di bawah:

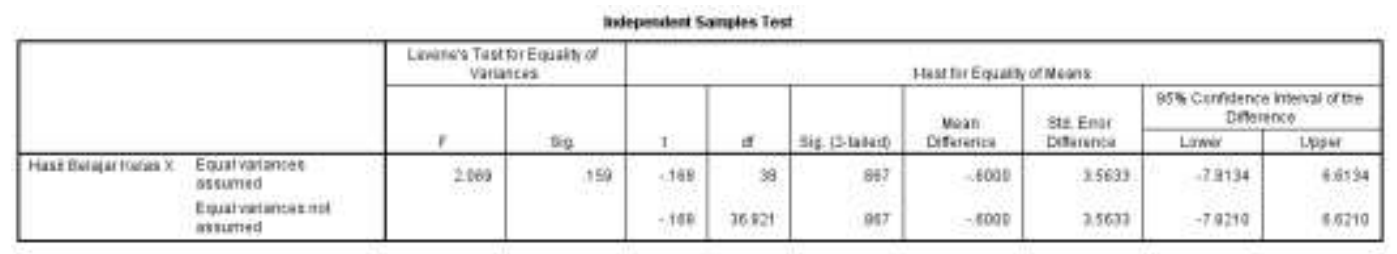

Gambar 4. Output independent sample test.

Dapat diketahu dari nilai Sig. Levene's Test for Equality of Variances adalah sebesar 0,159 yang artinya bahwa varians data antara kelas MIA 1 dan MIA 2 sebesar 0,159>0,05, yang artinya varians data antar kelas MIA 1 dan MIA 2 homogen atau sama.

Lalu, berdasarkan output pada bagian Equal Variances Assumed, diketahui nila Sig. (2-tailed) sebesar 0,867, yang artinya $0,867>0,05$, maka sebagaimana dasar pengambilan keputusan dapat disimpulkan bahwa $\mathrm{H}_{0}$ diterima dan $\mathrm{H}_{\mathrm{a}}$ ditolak. Jadi kesimpulannya bahwa tidak terdapat perbedaan yang signifikan atara hasil belajar kelas MIA 1 dan MIA 2.

Dari hasil pengujian di atas dapat di ambil kesimpulan, bahwa pemahaman siswa terhadap materi besaran, satuan, dan pengukuran dapat di katergorikan cukup baik. Tidak ada perbedaan yang signifikan antara kelas satu dengan yang lainnya, artinya hasil belajar dan pemahaman siswa kelas MIA 1 dan MIA 2 terhadap materi besaran, satuan, dan pengukuran hampir sama. Dari hasil tersebut, ada baiknya dilakukan penelitian lebih lanjut tentang upaya/cara untuk meningkatkan hasil belajar siswa terhadap materi fisika, dan peran guru di perlukan di sini untuk mengubah mindset peserta didik bahwa fisika bukanlah mata pelajaran yang harus ditakuti dan dihindari, sesuai dengan pendapat Suwondo (2019:39-40), berhasil atau tidaknya pencapaian pembelajaran tidak lepas dari guru dalam menerapkan model dan metode yang dapat mendorong siswa untuk belajar.

Setelah pola pikir itu berubah maka besar kemungkinan juga hasil belajar siswa terhadap materi fisika akan meningkat. Hal itu sesuai dengan pendapat Aminoto (2019:49), agar belajar fisika terasa lebih menyenangkan, maka manfaat 
P-ISSN 2580 - 7781

E-ISSN 2615 - 3238

belajar fisika perlu dipahami. Untuk menghadapi halangan atau kesulitan apapun ketika sedang belajar fisika motivasi belajar menjadi modal pertama.

\section{KESIMPULAN}

Setelah dilakukan penelitian dan pengujian data dari hasil belajar fisika materi besaran, satuan, pengukuran di MAN 2 Kota Jambi terhadap siswa kelas X MIA 1 dan 2 dapat disimpulkan, bahwa pemahaman siswa dan hasil belajar siswa terhadap materi besaran, satuan, dan pengukuran masih dikategorikan "cukup" yang artinya masih banyak perlu peningkatan pemahaman siswa terhadap mata pelajaran fisika, dengan adanya pendapat bahwa fisika adalah pelajaran yang sulit mampu mempengaruhi minat belajar siswa terhadap pelajaran fisika yang nantinya akan berefek pada hasil belajar siswa.

Peran guru dan orang tua sangat diperlukan disini, diharapkan guru mampu mengubah metode dan variasi dalam mengajar, agar pembelajaran fisika di dalam kelas tidak terkesan monoton dan mampu meningkatkan minat belajar siswa terhadap pembelajaran fisika. Dengan hal itu maka lambat laun hasil dan prestasi siswa terhadap pembelajaran fisika juga akan ikut meningkat, dan mindset siswa yang menganggap fisika adalah pelajaran yang sulit pun akan berubah apabila guru mampu menyuguhkan proses pembelajaran yang sesuai dengan kebutuhan siswa yang terkesan tidak monoton dan membuat siswa merasa kebingungan.

\section{DAFTAR PUSTAKA}

Aminoto, Tugiyo., Dani, Rahma., Yuversa, Edi. (2019) Pengembngan Termometer Gas Sebagai Alat Peraga Pembelajaran Pokok Bahasan Skala Suhu Mutlak. Jurnal Edufisika, 4 (2), 48-55.

Dani, Rahma., Latifah, Ayu , N., Putri, A, S. (2019). Penerpan Pembelajaran Berbasis Discovery Learning Melalui Metode Talking Stick Untuk Meningkatkan Pemahaman Konsep Gerak Lurus. Jurnal EduFisika. 4 (2), 24-38.

Jufrida., Basuki, Rahmat, F., Pangestu, D,M., Prasetya, Djati, A, N. (2019). Analisis Faktor yang Mempengaruhi Hasil Belajar IPA dan Literasi Sains di SMP Negeri 1 Muaro Jambi. Jurnal Edufisika. 4 (2), 31-38.

Kurnia, Nila., Hendri, Menza., Pathoni, Haerul. (2016). Hubungan Persepsi dengan hasil Belajar Kelas X MIA di SMA Negeri 4 Kota Jambi dan SMA Negeri 11 Kota Jambi. Jurnal Edufisika, 1(1), 55-63. 
P-ISSN 2580 - 7781

E-ISSN $2615-3238$

Oktaviana, Dina., Jufrida., Darmaji. (2016). Penerapan Berbasis Multiple Intelences Untuk meningkatkan Aktivitas dan hasil Belajar Fisika Siswa Pada Materi kalor dan Perpindahan Kalor kelas X MIA 4 SMA Negeri 3 Kota Jambi. Jurnal Edufisika. 1(1), 7-12.

Purwunto, Eko, A., Henri, Menza., Susanti, Nova. (2016). Studi Perbandingan Belajar Siswa Mengggunakan Media Phet Simulation Dengan Alat Peraga PAda Pokok BAhasan Listrik Magnet di Kelas IX SMPN 12 Kabupaten Tebo. Jurnal Edufisika, 1(1), 22-27.

Suwondo., Astalini., Darmaji. (2019). Penerapan Model Pembelajaran Kooperatif Tipe Time Token Untuk Meningkatkan Hasil Belajar Fisika Siswa. Jurnal Edufisika, 4 (2), 39-47.

Taqwa, Arief, R, M., Faizah, Refnika., Rivaldo, Lugi. (2019). Pengembangan Lembar Kerja Mahasiswa Berbasis POE dan Kemampuan Berpikir Kritis Mahsiswa pada Topik Fluida Statis. Jurnal Edufisika. 4(1), 6-13. 